\title{
Respiratory health and disease in Europe: the new European Lung White Book
}

\author{
G. John Gibson', Robert Loddenkemper², Bo Lundbäck ${ }^{3}$ and Yves Sibille ${ }^{4}$ \\ Affiliations: ${ }^{1}$ Newcastle University, Newcastle upon Tyne, UK. ${ }^{2}$ German Central Committee against \\ Tuberculosis (DZK), Berlin, Germany. ${ }^{3}$ Krefting Research Centre - Institute of Medicine, University of \\ Gothenburg, Gothenburg, Sweden. 'UCL Mont-Godinne, Yvoir, Belgium.
}

Correspondence: G.J. Gibson, Newcastle University, Newcastle upon Tyne, NE7 7DN, UK. E-mail: john.gibsonancl.ac.uk

0

@ERSpublications

The European Lung White Book-a major new overview of respiratory health in Europe http://ow.ly/n7kRq

http://ow.ly/n7kVX

10 years have passed since the European Lung White Book - The first comprehensive survey on respiratory lung health in Europe was published by the European Respiratory Society (ERS) together with the European Lung Foundation (ELF) [1]. Its aims were to highlight the enormous and underestimated health and socioeconomic burdens of respiratory disease in Europe and to inform decision-makers in national health authorities and the European Union (EU) about the importance of lung health and respiratory disease showing the enormous burden of lung disease in Europe [2].

The White Book was launched with a presentation to members of the European Parliament in Brussels, Belgium in November 2003, with forewords written by the then EU Commissioner for Health and Consumer Protection, David Byrne, and the Director General of the World Health Organization (WHO), Gro Harlem Brundtland, testifying to the importance of the publication and to the increasing recognition by both the EU and $\mathrm{WHO}$ of the burden of respiratory disease. To disseminate the message more widely, an abbreviated version entitled Lung Health in Europe: Facts \& Figures (aka the "small White Book") [3] was published by ELF in 10 languages (English, Danish, Dutch, French, German, Greek, Italian, Polish, Russian and Spanish).

The information provided by the White Book was well received both by health professionals and those responsible for organising healthcare. It has been widely used by health policy-makers at the EU and national levels and led to inclusion by the EU and UN of respiratory diseases among the major noncommunicable chronic diseases [4].

The White Book was subsequently a key component of a global public health awareness campaign supported by the ELF: the "Breath of Life" campaign. This campaign, restricted initially to lung health and disease, has been widened by initiatives involving other European medical societies addressing the issue of chronic disease in general, leading to the foundation of the European Chronic Disease Alliance [5] and the Alliance for Biomedical Research in Europe [6].

The ERS initiative was later followed by publication by the American Thoracic Society of Breathing in America [7] and this year the Forum of International Respiratory Societies (FIRS) will publish Respiratory Diseases in the World: Realities of Today, Opportunities for Tomorrow, stressing the worldwide dimension of respiratory health [8].

As well as influencing policy-makers, a major aim of the first White Book was to raise awareness among the media and general public of the importance of respiratory diseases and measures necessary to counter their

Received: June 202013 | Accepted: June 212013

Conflict of interest: Disclosures can be found alongside the online version of this article at www.erj.ersjournals.com 
increase. At that time, for example, it was not widely appreciated that the global mortality due to respiratory disease (with four amongst the ten leading causes of death: pneumonia, chronic obstructive pulmonary disease (COPD), lung cancer and tuberculosis) exceeded that due to cardio- and cerebrovascular disease.

The White Book also detailed, for the first time, the financial impact of respiratory disease across the whole of Europe (i.e. the European region as defined by the WHO) with direct and indirect health costs estimated to exceed $€ 100$ billion.

In the past 10 years, the EU has expanded from 15 to 28 member countries and to 505 million inhabitants and the ERS considers it timely to update the information in the White Book in order to illustrate how the specialty is changing and how recent trends are influencing practice.

The new White Book has a similar structure to the original and is divided into six sections:

Section A comprises an overview of the burden of lung disease in Europe and its economic impact. Globally in 2008, mortality from respiratory disease continued to exceed that due to cardio- and cerebrovascular disease. In Europe, mortality from respiratory disease ranked third overall, accounting for about one-tenth of all deaths (table 1$)$.

Respiratory diseases cause about 1 million deaths annually in the WHO European Region, of which twothirds occur in the 28 countries of the EU. However, as shown in figure 1, mortality rates from respiratory disease vary appreciably between European countries, with the highest rates in parts of north-western Europe (Belgium, Denmark, Ireland and the UK), central Europe (Hungary, Romania and Moldova) and some central Asian republics (Kazakhstan and Kyrgyzstan).

Lung cancer is the leading cause of respiratory death, followed by COPD, lower respiratory infections and tuberculosis. More than half of all the deaths from respiratory disease (and at least one-quarter of all respiratory hospital admissions) are due to diseases caused by smoking. It is predicted that lung cancer and COPD as causes of death will continue to rise until 2015 and 2030 respectively (table 2).

Due to a paucity of data on several diseases and from most non-EU countries, analysis of the economic impact of respiratory disease has been limited to the EU and to the commoner diseases. In brief, the estimated annual total of conventional direct (healthcare) plus indirect (loss of productivity) costs of asthma, COPD, lung cancer, tuberculosis, acute respiratory infections, cystic fibrosis and obstructive sleep apnoea syndrome (OSAS) in the $28 \mathrm{EU}$ countries is at least $€ 96$ billion. If, in addition, the monetised value of disability-adjusted life-years lost due to disability and premature death is included, the total cost exceeds a staggering $€ 380$ billion. It should be borne in mind that due to inability to cost many conditions, even these totals are significant underestimates of the overall socioeconomic burden of respiratory disease in the EU.

Section B considers the major risk factors for respiratory disease, in particular tobacco smoking and environmental and occupational agents as well as genetic and early-life events. The 20th-century epidemics of both COPD and lung cancer are closely related to the epidemic of smoking but with a lag of 20-30 years. There has been an encouraging decline in tobacco consumption in many developed countries over the past 30 years, but in others, smoking rates remain depressingly high. Where smoking has declined, the prevalence of COPD in males has started to level off, but this is not yet the case in females and lung cancer continues to increase in both sexes. Although a reduction in both conditions is anticipated eventually, the considerable time lag between tobacco exposure and the development of disease implies that both will

\section{TABLE 1 The 10 most common causes of death in 2008}

\begin{tabular}{|c|c|c|}
\hline Deaths attributed to & Worldwide & WHO European Region \\
\hline Ischaemic heart disease & 7.3 million (12.8\%) & 2.40 million $(24.7 \%)$ \\
\hline Cerebrovascular disease & 6.2 million (10.8\%) & 1.40 million $(14.0 \%)$ \\
\hline Lower respiratory infections & 3.5 million $(6.1 \%)$ & 0.23 million $(2.3 \%)$ \\
\hline COPD & 3.3 million $(5.8 \%)$ & 0.25 million $(2.5 \%)$ \\
\hline Diarrhoeal diseases & 2.5 million $(4.3 \%)$ & 0.03 million $(0.3 \%)$ \\
\hline HIV/AIDS & 1.8 million (3.1\%) & 0.08 million $(0.8 \%)$ \\
\hline Trachea/bronchus/lung cancer & 1.4 million $(2.4 \%)$ & 0.38 million $(3.9 \%)$ \\
\hline Tuberculosis & 1.3 million $(2.4 \%)$ & 0.08 million $(0.8 \%)$ \\
\hline Diabetes mellitus & 1.3 million (2.2\%) & 0.17 million (1.7\%) \\
\hline Road traffic accidents & 1.2 million $(2.1 \%)$ & 0.12 million $(1.2 \%)$ \\
\hline
\end{tabular}

WHO: World Health Organization; COPD: chronic obstructive pulmonary disease. Data in bold refer to respiratory related deaths. Data from [9]. 


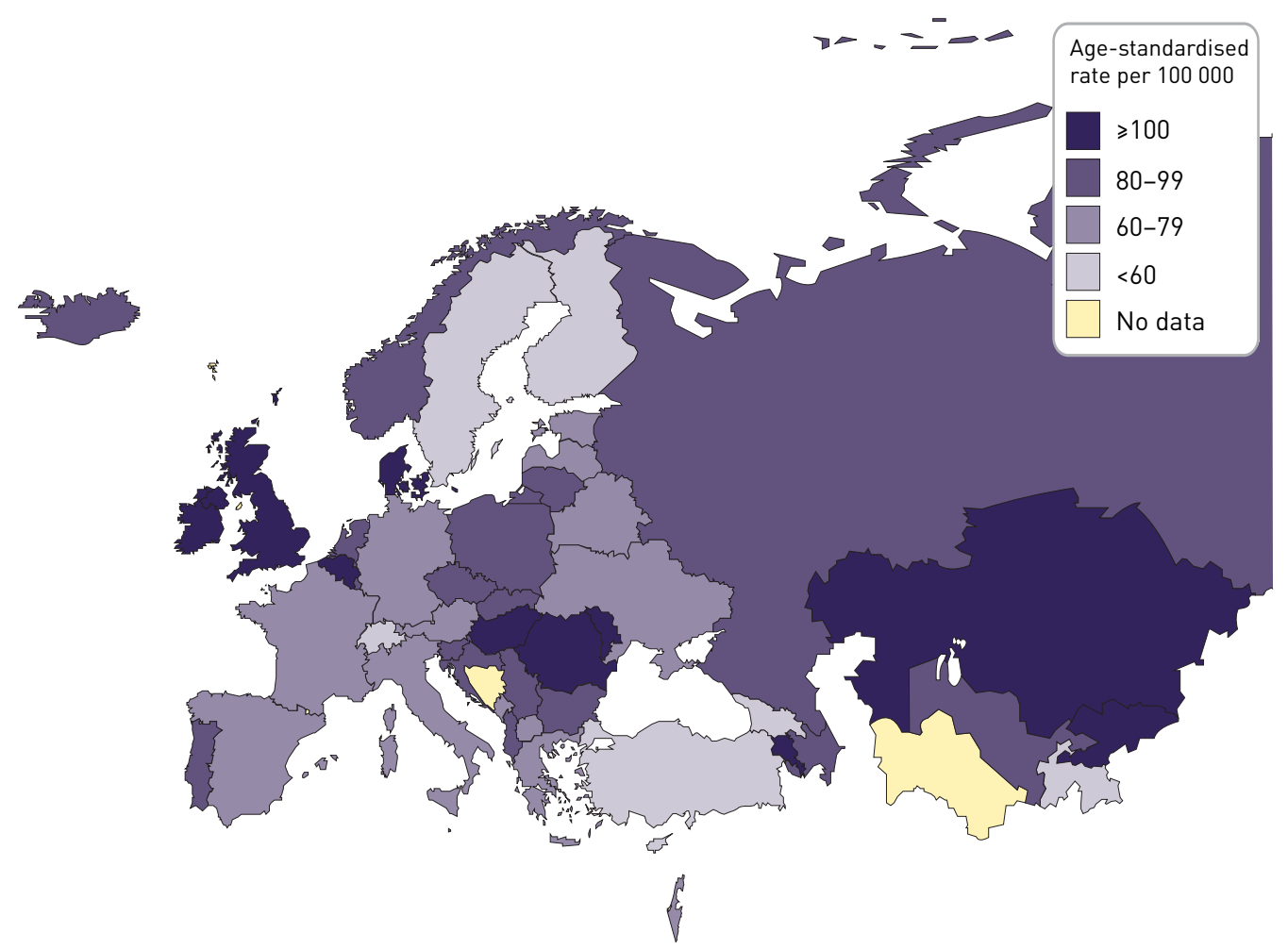

FIGURE 1 Map of age-standardised mortality rates for all respiratory conditions. Data from [10].

remain major challenges for several decades yet. Furthermore, in some countries tobacco consumption has so far shown little decline and in many less developed countries it is still increasing.

Both the indoor and outdoor environments are increasingly recognised as major contributors to respiratory disease, with pollution from passive smoking and vehicle exhaust fumes now established causes alongside the classical occupational agents. All are highly relevant to the public health policies of both the EU and national authorities aimed at optimising the quality of the air we breathe.

Section $\mathrm{C}$ is dedicated to the major childhood and adult respiratory diseases, which are defined in terms of incidence, prevalence, mortality, and future requirements for improving patient care and for research.

Asthma increased in prevalence in many countries in the late 20th century; the precise reason(s) remain unclear but are in some way related to the "western" lifestyle and increasing urbanisation. Although the peak of this asthma "epidemic" seems to be passing in western Europe, evidence suggests that in many eastern European countries the prevalence of asthma is "catching up" as socioeconomic conditions improve and the lifestyle approaches that of western countries.

The prevalence of COPD, already very high (fig. 2), is likely to continue increasing until at least 2030. The same is true for lung cancer, which is the biggest cancer killer in Europe, accounting for approximately $20 \%$ of all cancer deaths and for the loss of 3.2 million disability-adjusted life-years annually across the region.

\begin{tabular}{|c|c|c|c|}
\hline Percentage of deaths in WHO European region & 2008 & 2015 & 2030 \\
\hline Lower respiratory infections & 2.3 & 2.2 & 1.9 \\
\hline COPD & 2.5 & 2.7 & 3.2 \\
\hline Trachea/bronchus/lung cancer & 3.9 & 3.9 & 4.1 \\
\hline Tuberculosis & 0.8 & 0.7 & 0.4 \\
\hline
\end{tabular}

Data from [9]. 


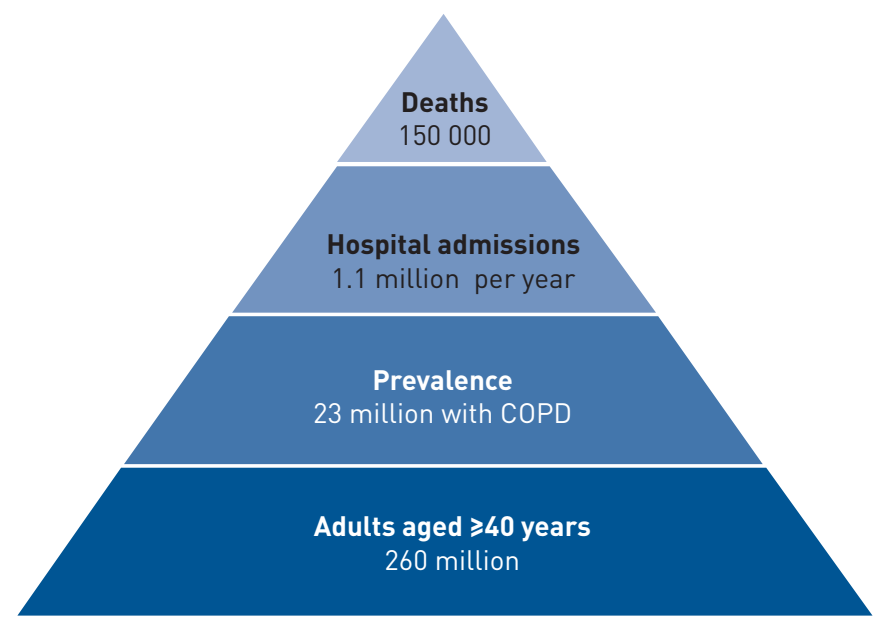

FIGURE 2 Chronic obstructive pulmonary disease (COPD; Global Initiative for Chronic Obstructive Lung Disease stages II-IV) burden in adults aged $>40$ years in the 28 European Union countries. An additional 17 million adults aged $\geqslant 40$ years had stage $I$ COPD.

The prevalence of some other respiratory conditions is also increasing. In this context, the most noteworthy development in the past 30 years is appreciation of OSAS as a major health and social problem. In retrospect, it is clear that the condition has been with us for centuries but it is only since the 1970s that it has been recognised as a major and common cause of morbidity. Although by no means restricted to the obese, it is closely related to weight and the observed increase is not just a matter of better recognition, but also represents a truly rising prevalence as obesity becomes more common. Also increasingly important for adult respiratory practice are events and disease in infancy and childhood: for example, the progressively improving survival of patients with cystic fibrosis means that it is now an important disease of adults; and the dramatically improved survival rate of very premature infants brings its own respiratory complications, which are now being seen in older children and young adults.

Infectious diseases continue to play a major role in respiratory medicine. Community-acquired pneumonia is the most frequent cause of death from infection in Europe; although the majority of patients with pneumonia are treated at home, about 1 million are hospitalised annually in the EU. Lack of new antibiotics and expanding resistance to established agents are increasingly important threats to health, with 10-15\% of isolates of Streptococcus pneumoniae now resistant to commonly used penicillin and/or macrolide antibiotics. Influenza usually affects the very young and the old, but the H1N1 pandemic hit younger adults particularly hard. Each year, in the WHO European region almost 400000 new cases of tuberculosis are diagnosed and more than 40000 people die of the disease. Tuberculosis is particularly problematic in several countries of the former Soviet Union, where multidrug-resistant tuberculosis is also highly prevalent. The proportion of tuberculosis patients with HIV infection among all tuberculosis cases tested for the virus in the WHO European region is increasing by $20 \%$ a year. Constant surveillance is also necessary for recognition of novel respiratory pathogens as exemplified by the emergence of the severe acute respiratory syndrome (SARS) virus in 2010 and the even more recent Middle Eastern respiratory syndrome coronavirus [11].

Section D describes the principles of management of respiratory disease: vaccination as the major preventive measure (e.g. against influenza, pneumococcal pneumonia and tuberculosis), principles of investigation, including modern imaging, endoscopic and molecular techniques and of treatment including pulmonary rehabilitation.

Section E focuses on special fields of respiratory care (paediatric respiratory medicine, respiratory intensive care and thoracic surgery).

This is followed by section $\mathrm{F}$ on practising respiratory medicine in Europe. The latter explains the roles of medical respiratory specialists, specialist nurses, allied respiratory professionals and primary care practitioners in caring for patients with respiratory disease. In addition this section covers specialist clinical training (the Harmonised Education in Respiratory Medicine for European Specialists), postgraduate education (ERS School) and the importance of respiratory research, respiratory journals and patient support organisations, in particular ELF. The chapter on specialist physicians includes information on the numbers of respiratory specialists in most European countries, data gathered with the assistance of ERS national delegates and national specialist societies.

The White Book closes with recommendations for European governments to improve and standardise surveillance and to implement various policy interventions aimed to optimise the provision of clinical facilities for investigating and treating respiratory disease and to increase funding for basic, translational and 
epidemiological research, so that in the future, the quality of care of patients with respiratory disease and comorbidities will reach a uniformly high level across Europe.

The publication of the new White Book has been possible only with the help of a large number of experts, with more than 100 individuals (editors, authors and reviewers) from all over Europe contributing. The data presented were generated from several sources including the European Union, the European Centre for Disease Prevention and Control, the WHO and its European Region and the Organisation for Economic Co-operation and Development. Despite these numerous sources, including informations from national delegates and national respiratory societies, data are often incomplete or missing for several countries; another aim of the publication is to highlight these deficiencies and the urgent need for them to be addressed, despite the present economic crisis in Europe [12].

As well as being published in print form, the full text, together with interactive maps and supplementary information, is available online with open access at whitebook.ersnet.org

We hope that this new White Book (together with the supporting infographic and factsheets being produced in several European languages by the European Lung Foundation (www.european-lung-foundation.org) will help to inform decision-making about the future provision of healthcare for patients with respiratory disease and to highlight the diseases for which more facilities and resources are likely to be required, as well as areas where further research is most needed. Specialists in respiratory medicine will appreciate that, in contrast to specialties with a universally recognised single name (e.g. cardiology, neurology), our specialty suffers from having several synonyms, with specialists known variously as respiratory physicians, pneumologists, pulmonologists, respirologists, lung doctors, chest physicians, thoracic physicians or, still in some countries, phthisiologists. This variation blurs the identity of the specialty and causes confusion among policy-makers and the general public. Hopefully, publication of the new White Book will increase awareness and appreciation of a very broad specialty and of the enormous impact of the many diseases which it encompasses.

\section{References}

1 Loddenkemper R, Gibson GJ, Sibille Y, eds. European Lung White Book: the First Comprehensive Survey on Respiratory Health in Europe. Sheffield, European Respiratory Society Journals, 2003.

2 Loddenkemper R, Gibson GJ, Sibille Y. The burden of lung disease in Europe: why a European White Book on lung disease? Eur Respir J 2003; 22: 869.

3 Loddenkemper R, Gibson GJ, Sibille Y, eds. Lung Health in Europe: Facts \& Figures. Sheffield, European Respiratory Society Journals, 2003.

4 United Nations General Assembly. Political declaration of the High-Level Meeting of the General Assembly on the Prevention and Control of Non-communicable Diseases. A/66/L.1. www.un.org/ga/search/view_doc.asp?symbol= A/66/L.1 Date last updated: September 16, 2011. Date last accessed: July 5, 2013.

5 European Society of Cardiology, European Society of Hypertension, European Cancer Organisation, European Association for the Study of the Liver, International Diabetes Federation (Europe), European Heart Network, European Respiratory Society, European Society for Medical Oncology, European Kidney Health Alliance, Foundation of European Nurses in Diabetes. European Chronic Disease Alliance. A Unified Prevention Approach. Sophia Antipolis, European Chronic Disease Alliance, 2010. www.escardio.org/about/what/advocacy/Documents/ Chronic-disease-alliance-final.pdf Date last accessed: June 20, 2013.

6 Nicod LP, Kamel N, Ward B, et al. ERS is founding member of a new Alliance for Biomedical Research in Europe. Eur Respir J 2011; 38: 237-238.

7 Schraufnagel DE, ed. Breathing in America: Diseases, Progress, and Hope. New York, American Thoracic Society, 2010.

8 Forum of International Respiratory Societies. Respiratory Diseases in the World: Realities of Today, Opportunities for Tomorrow. Lausanne, Forum of International Respiratory Societies, 2013.

9 World Health Organization. World Health Statistics 2011. Geneva, World Health Organization, 2011. http://www. who.int/entity/whosis/whostat/EN_WHS2011_Full.pdf Date last accessed: June 20, 2013.

10 World Health Organization World and Europe Detailed Mortality Databases. http://data.euro.who.int/dmdb/ Date last accessed: June 20, 2013.

11 de Groot RJ, Baker SC, Baric RS, et al. Middle East Respiratory Syndrome Coronavirus (MERS-CoV): announcement of the Coronavirus Study Group. J Virol 2013; 87: 7790-7792.

12 Mackenbach JP, Karanikolos M, McKee M. The unequal health of Europeans: successes and failures of policies. Lancet 2013; 381: 1125-1134. 